\title{
Considerações sobre o conceito de campesinato para Alta Idade Média
}

\section{Considerations about the concept of peasantry in the Early Middle Ages Consideraciones sobre el concepto de campesinado para la Alta Edad Media}

\author{
Eduardo Cardoso Daflon \\ ec.daflon@gmail.com \\ Programa de Pós-Graduação em História. \\ Universidade Federal Fluminense (PPGH-UFF), \\ Brasil
}

Recepção: 01 Fevereiro 2020

Aprovação: 25 Julho 2020

Publicação: 01 Março 2021

Cita sugerida: Cardoso Daflon , E. (2021). Considerações sobre o conceito de campesinato para Alta Idade Média. Sociedades Precapitalistas, 11, e056. https://doi.org/10.24215/22505121e056
Resumo: Para abordar uma série de realidades rurais, temporal e espacialmente diversas, é frequente a mobilização do termo "camponês" que tem uma larga tradição de estudos existente nas Ciências Humanas que remonta pelo menos ao século XIX. Porém, desde os anos 1980 houve uma redução expressiva no número de trabalhos com foco nesses agentes sociais. Para o mundo pré-capitalista em geral - e o medieval em particular - temos a existência de sociedades cuja absoluta maioria da população vive no campo e tira seu sustento, majoritariamente, do trabalho agrícola. Por sua vez, esses longevos anos de reflexão sobre o campesinato não encontraram eco marcante nos estudos do medievo, com aqueles que trabalhavam o solo merecendo de medievalistas, comparativamente, muito menos atenção que a aristocracia. Apesar disso, o termo "camponês" não é raro, aparecendo normalmente desprovido de uma reflexão conceitual mais aprofundada. O presente trabalho busca argumentar que a aplicação de uma conceituação mais precisa do campesinato permitirá ganhos analíticos e de compreensão historiográfica desse grupo internamente e historicamente heterogêneo. Para tanto, elabora-se uma breve revisão da bibliografia disponível e com base nela propõe-se uma maneira de abordar teoricamente o campesinato (alto)medieval.

Palavras-chave: Camponês, Campesinato, Idade Média, Teoria.

Abstract: The word "peasant" is frequently used to address a series of rural realities, very diverse points in time and space. It is a term with a long tradition in the Humanities, which goes back at least to the $19^{\text {th }}$ century. However, since the 1980's there was a dramatic shortage in works focused on this social actors. For the pre-capitalist world in general - and the medieval in particular - we have societies with the absolute majority of the population based in the countryside living from the work in the fields. In spite ofthat, peasant studies did not find great repercussion in medievalism; aristocracies tend todeservemuch more attention from historians than those who cultivate the soil. As result, although the word peasant is not rare in medieval history, it does not come along with a deeper conceptual reflexion. The present text argues that a more precise use of the concept of "peasantry" 
would bring analytical and historiographical gains to the research of this historically heterogeneous group. With this in mind, a bibliographicrevision is made in order to propose a theoretical approach to the (early) medieval peasantry.

Keywords: Peasant, Peasantry, Middle Ages, Theory.

Resumen: Para abordar una serie de realidades rurales, tanto temporal como espacialmente diversas, se utiliza con frecuencia el término "campesino", que tiene una larga tradición de estudios existentes en las Ciencias Humanas que se remonta al menos al siglo XIX. Sin embargo, desde la década de los 80 , se ha producido una reducción significativa en el número de trabajos centrados en estos agentes sociales. Para el mundo precapitalista en general, y el medieval en particular, tenemos sociedades cuya mayoría absoluta de la población vive en el campo, principalmente, del trabajo agrícola. Sin embargo, estos prolongados años de reflexión sobre el campesinado no encontraron un eco marcado en los estudios medievales, por el contrario, la aristocrática cautivó más la atención de los medievalistas que aquellos que trabajaban la tierra. A pesar de eso, el término "campesino" no es infrecuente, pero aparece normalmente desprovisto de una reflexión conceptual más profunda. El presente trabajo busca argumentar que la aplicación de un concepto más preciso del campesinado permitirá avances analíticos y comprensión historiográfica de este grupo interna e históricamente heterogéneo. Con ese objetivo se elabora una breve revisión de la bibliografía disponible y en base a ella se propone una forma de acercarse teóricamente al (alto) campesinado medieval.

Palabras clave: Campesino, Campesinado, Edad Media, Teoría.

Falar ${ }^{1}$ em campesinato para o contexto medieval pode parecer algo autoevidente, sendo muitas vezes encarado como tão óbvia a existência de um campesinato em sociedades pré-capitalistas que na historiografia dedicada à Idade Média raras vezes houve uma reflexão conceitual cuidadosa. Algo mais marcante para a Alta do que para a Baixa Idade Média, visto que na segunda, pelo menos, o campesinato foi objeto de estudos mais sistematizados.

Contudo, o termo "camponês" em si não é raro, frequentemente aparecendo de maneira vaga, gerando uma série de problemas de análise por não ficar claro a quais agentes sociais se refere. Portanto, aqui não farei uma revisão historiográfica acerca do emprego do conceito de campesinato. Desejo com esse texto refletir sobre qual o conteúdo sociológico essa palavra possui e como seu uso mais preciso pode auxiliar aos historiadores a compreender melhor os primeiros séculos medievais.

Muitas vezes se trata os camponeses como aqueles que se mantêm independentes em relação aos poderes senhoriais (Bernardo, 1995, p.15-16). Ou seja, chega-se a negar o emprego da palavra "camponês" para qualquer um que não goze de uma condição de liberdade absoluta em relação aos poderes aristocráticos. Algo que limita em muito a utilidade conceitual, visto que há uma enorme diversidade interna daqueles que trabalham o solo.

No outro extremo, o conceito de campesinato é generalizado para todos os que produzem alimentos nessas sociedades, embaçando qualquer especificidade 
(Wickham, 2005: 386), o que nos faz perder de vista o desenvolvimento histórico das condições de exploração perpetrada pelas aristocracias e nos dificulta a compreensão dos mecanismos utilizados para avançar a dominação. Além disso, temos maior dificuldade de analisar as disputas internas às comunidades e aldeias de maneira integrada.

Uma terceira possibilidade é aquela que torna "campesinato" um conceito inócuo que se perde no meio de uma série de concepções de época, normalmente vinculadas à diferenças jurídicas (Bastos, 2010). Essas apontam para uma variedade de formas de dependência pessoal - tais como seruus, coloni, mancipia, ancilla, liberti - ou dominação através de termos como dominus e patronus. Além de uma série de palavras correntes que denotam relações de cunho pessoal, como obsequium, patrocinium, servitium, reverentia, bumilitas, servitus, fidelis, infidelis, obedientia, gratia libertatis, fidelitas, famulatus, infidelitas, inobetientis, ingratus, perfidia.

Dessa forma, o objeto primordial deste texto é promover uma reflexão teórica que nos permita falar em um "camponês" medieval, de forma a termos um conceito operacional que nos possibilite dar conta da diversidade desses sujeitos e das tensões com a classe dominante no processo histórico da luta de classes.

Vale destacar que a questão do campesinato ainda não mereceu da historiografia da Alta Idade Média Ibérica um tratamento sistemático. Assim, ela aparece apenas sendo um tema lateral em debates bastante clássicos, especialmente aqueles em torno da transição da Antiguidade ao Feudalismo (Anderson, 1994; Barbero e Vigil, 1978) ou da passagem do escravismo à servidão (Bloch, 1998).Vejamos, então, como o campesinato foi teoricamente apreendido no campo das Ciências Humanas a fim de que possamos nos valer desse conhecimento acumulado e propor aplicaçóes direcionadas ao estudo do período altomedieval.

\section{Breve histórico do conceito}

Talvez convenha começar essa breve revisão por uma definição bastante abrangente como aquela proposta recentemente aprovada pela Organização das Naçes Unidas. No documento intitulado Declaration on the Rights of Peasants and Other People Working in Rural Areas, a Assembleia Geral considerou camponês, basicamente, qualquer pessoa que trabalha (ou busca trabalhar) em atividades ligadas à terra, à pesca, à caça, à coleta e ao artesanato no campo (ONU, 2018, p. 4-5).Essa definição abre um amplo escopo de possibilidades, o suficiente para incluir mesmo grupos como caçadores e coletores, os quais dificilmente seriam incorporados dentro de uma conceituação científica. Isso porque esses guardam radicais diferenças societárias e de organização do trabalho e da vida (Edelman, 2013).

Como forma de obter uma leitura mais precisa, os autores das Ciências Sociais estabeleceram algumas distinções fundamentais entre os caçadorescoletores e "aqueles propriamente camponeses", necessárias, dado o fato de que as configurações destes grupos são bastante distintas em termos sociológicos. Claude Meillassoux (1973, p. 82), por exemplo, estabelece que a principal diferença entre os grupos caçadores-coletores e o campesinato é a relação que ambos têm com os recursos naturais. Segundo a perspectiva de Meillassoux, para 
os primeiros a terra é sujeito do trabalho, e para os segundos um instrumento de trabalho. Outra possibilidade frequentemente apontada é que a capacidade de articulação destas sociedades baseadas na caça e na coleta seria tendencialmente menor, relacionando-se com grupos humanos que vivem em uma área restrita.

Essas, contudo, talvez não sejam as melhores formas de diferenciar ambos conceitualmente, tendo em vista que os camponeses têm fases produtivas que supõem a complementação com caça e coleta (Wolf, 1976, p. 13-16). Além disto, é sabido desde Malinowski $(1978)^{2}$ que grupos não-agrícolas podem estabelecer laços por longas distâncias, como no caso dos navegantes do Pacífico.

No mesmo sentido da proposição da ONU, temos a definição "guarda-chuva", feita pela Via Campesina, que defende a ideia de união dos povos do campo, englobando uma diversidade de grupos, ao ponto que o "termo camponês pode ser aplicado para qualquer pessoa envolvida na agricultura, criação de animais, pastoralismo, artesanato relacionado à agricultura ou uma ocupação relacionada a uma área rural." (Via Campesina, 2009)

Essa definição de organismos internacionais, como a das Nações Unidas, está bastante imbuída de uma reflexão política de preservação do meio ambiente e de preocupação com a elaboração de políticas governamentais em escala global. Já os movimentos sociais buscam articular a maior quantidade possível de pautas e de grupos sociais do campo, visando fortalecer a luta e ampliar sua base de sustentação.

Essa preocupação em ocupar espaços como a Assembleia Geral, no mínimo, já sinaliza o quão político é esse debate, que tem ganhado a arena pública, sobretudo a partir da segunda metade dos anos 1990, após a aliança global dos movimentos camponeses através da Via Campesina. Ambos os caminhos apresentados são legítimos para as lutas sociais, mas oferecem poucos subsídios de análise social, sendo necessário ver como as Ciências Sociais vêm realizando esta discussão.

Genericamente, o histórico do conceito de "camponês" pode ser dividido em dois grandes blocos de estudos, chamados por Sevilla Guzmán e González de Molina (2013, p. 9-14) de "antiga tradição" e "nova tradição". Essas discussões remontam pelo menos ao século XVIII, num primeiro momento fruto de trabalhos isolados durante a gênese do pensamento agrário desde uma perspectiva científica.

Uma primeira corrente de pensamento se constituiu com os "populistas russos" - também conhecidos como "narodnistas" - que surgem da reflexão sobre as comunidades camponesas russas, suas formas de gestão e direito consuetudinário. Os narodnistas, ao longo do XIX, incorporaram leituras d'O Capital e começaram a desenvolver, com gradações e diferenças entre si, um modelo de desenvolvimento econômico não-capitalista para a Rússia.

Nesse bojo, temos ainda autores como Bakunin (1870) e Kropotkin (1893), começando a defender uma transição a um outro modelo societário sem a destruição do campesinato. Conforma-se, desta maneira, o anarquismo agrário que interpreta o camponês como um agente revolucionário (Sevilla Guzmán e González de Molina, 2013, p. 30-38). Assim, tendo em vista sua forma de organização coletiva, tendencialmente igualitária e de apoio mútuo, as comunidades camponesas teriam o que oferecer a uma nova ordem social.

Por sua vez, os trabalhos da juventude de Marx- especialmente $O 18$ de Brumário de Luis Bonaparte - são assimilados de maneira peculiar pelos 
intelectuais vinculados à II Internacional, desconsiderando seus escritos mais tardios (Löwy, 2013, p. 13-14). Marx (2011, p. 142-143), a essa altura, guardava uma visão pejorativa acerca do campesinato, vendo-o como conservador, isolado e incapaz de qualquer articulação política mais ampla.

Kautsky (1980) é o principal representante desse movimento no que se refere aos estudos agrários, desenvolvendo concepções um tanto dogmáticas acerca do campesinato, teoricamente rígidas, que apontam para uma postura evolucionista, unilinear, apresentando as mudanças agrárias como sendo um mero reflexo de transformações globais na sociedade. Desta maneira, toma-se o campesinato como um ente passivo, um mero joguete nas mãos de forças externas.

Visão dogmática que sabemos que Marx e Engels (2013) não compartilhavam, visto que nos seus últimos anos de vida passaram a refletir sobre a multilinearidade do desenvolvimento histórico. Assim, em diversas cartas avançaram sobre a possibilidade de um futuro não-capitalista para a Rússia através da comunidade rural, com grande destaque à carta de Marx para Vera Zasulitch de 1881; ou seja, viam na comuna rural um caminho para a regeneração social da Rússia - leia-se implicitamente socialismo (Löwy, 2013, p. 11) - caso ocorresse a Revolução (Musto, 2018).

Mesmo Lênin (2017, p. 48), que ainda aceitava ajustes na teoria a fim de dar conta da realidade objetiva, pensava que no quadro da transição ao socialismo o campesinato não seria um agente revolucionário; ao contrário, apontava que esse seria um grupo possível de ser fracionado pelo capital, e que no processo de desenvolvimento socialista deveria deixar de existir.

Isso, por consequência, leva à ideia de que o campesinato seria um ente característico de sociedades pré-capitalistas, e que, tanto o capitalismo quanto o socialismo, trariam como consequência intransponível o seu desaparecimento. Visões rígidas que seriam ainda mais endurecidas pela afirmação do stalinismo e sua imposição de um "marxismo engessado", que deixou de ser uma ferramenta de explicação da realidade para ser utilizada como um modelo de aplicação universal.

Interlocutor fundamental neste processo é Aleksadr Chayanov (1981), autor neopopulista que escreve nos anos 1920 e se dedica à análise das transformaçóes do campo antes e após a Revolução Russa, e que considera o campesinato marcado por características tão específicas que lhe daria uma coerência analítica. Seria um grupo social estranho ao capitalismo, uma vez que desconheceria categorias como trabalho assalariado ou a impossibilidade de aplicar o cálculo capitalista do lucro. Assim, a relação com a terra ou a autoexploração familiar de forma não assalariada, bem como as relações intracomunitárias, seriam fatores importantes para a definição do conceito de "camponês" na perspectiva chayanoviana. Para ele, portanto, não difeririam em sua lógica organizativa um camponês livre ou um servo no contexto medieval.

Temos, então, duas linhas teóricas acerca do campesinato entre fins do XIX e meados do XX: 1. A visão etapista - liberal ${ }^{3}$ ou de esquerda - do campesinato como um estorvo social herdado de sociedades pré-capitalistas, fadado à extinção pelo desenvolvimento da industrialização, de maneira unilinear e inevitável e; 2. Uma postura que vê o campesinato com forte capacidade de adaptação histórica, inserindo-se e tendo o potencial de reproduzir diversos modos de produção.

A renovação desses estudos se dá a partir da segunda metade do século XX com a formação dos chamados peasant studies (estudos camponeses), 
cujos principais representantes talvez sejam Eric Wolf e Teodor Shanin. A principal contribuição do primeiro são as íntimas relações entre as tipologias de campesinato relacionadas ao ambiente em que as comunidades estão inseridas expressando sua diversidade histórica e social (Wolf, 1976, p. 35-59). Por sua vez, o segundo tem o mérito de romper com unilinearidade do desenvolvimento social característico do narodnismo ou das interpretaçóes realizadas a partir de um marxismo enrijecido, propondo multilinearidades para o desenvolvimento dos países periféricos. Ou seja, Shanin colabora para mostrar como comunidades camponesas, com sua lógica de estruturação, são inseridas no bojo de uma sociedade capitalista, contribuindo para sua reprodução.

Nesse sentido, a nova tradição dos estudos camponeses se constrói teoricamente sobre a antiga, especialmente com base nos estudos de Chayanov. Contudo, as definições ficam menos rígidas, ainda que se mantenha a construção teórica permeada por categorias gerais que permitem o uso amplo desse conceito. Assim, o foco deixa de ser o campesinato isolado e passa-se a ter mais atenção à relação do campesinato com elementos externos, tais como o mercado, por exemplo.

Além disso, temos a tentativa de diminuir o vão que existe entre a abstração "camponês" e aquele ente existente na prática social. Dessa forma, Sidney Mintz (1973, p. 92), outro importante membro da nova tradição dos peasant studies, adverte que precisamos ter um conceito de campesinato que possa lidar com problemas impostos pela realidade. Assim, precisamos estar atentos: 1) à variedade interna do campesinato; 2) à relação do campesinato, ou de subgrupos do campesinato, entre si e com outros setores não rurais; 3 ) ao uso de fatores culturais ou comunitários para definir o campesinato; 4) ao significado da história para o desenvolvimento de uma tipologia de campesinato. Trata-se de evitar uma encruzilhada teórica que circunscreve em demasia este recurso teórico, deixandoo suficientemente aberto para dar conta da realidade.

Dito isso, vejamos as definições de proposta por essa "nova tradição" dos estudos camponeses. Teodor Shanin afirma que o campesinato é mais do que uma construção teórica, sendo uma realidade vivida e experimentada por milhões ao redor do mundo. Contudo, por se tratar de um agente com manifestações tanto no presente quanto no passado, devemos estar atentos para o fato de que não se trata de um grupo igual a ele mesmo ao longo de toda a história. Mas, ao contrário, trata-se de um grupo profundamente marcado por características próprias a depender do desenvolvimento técnico e do ambiente em que está inserido, como nos lembrou Wolf.

Dessa maneira, é possível perceber o conceito de campesinato como útil e suficientemente maleável para apreender os diversos contextos em que aqueles que lavram a terra estão inseridos. Isso, desde que seja associado a outros que permitem explicar o conjunto das relações de dominação manifestas em determinado momento histórico, como ao de forças produtivas e de relaçóes sociais de produção.

Uma proposição metodologicamente interessante é a proposta por Eric Wolf. Para ele, aquilo que define o campesinato é a tipologia dos laços constituídos. Enquanto nas sociedades "primitivas" os produtores possuem os meios de produção, inclusive da distribuição do trabalho, nas sociedades camponesas 
temos a presença de grupos que não cultivam a terra, mas que precisam ser alimentados. Ou seja:

(...) os camponeses (...) são cultivadores rurais cujos excedentes são transferidos para as mãos de um grupo dominante, constituído pelos que governam, que os utilizam para assegurar seu próprio nível de vida, e para distribuir o restante entre grupos da sociedade que não cultivaram a terra, mas que devem ser alimentados, dando em troca bens específicos e serviços. (Wolf, 1976, p. 16)

Assim sendo, pode-se ter um instrumento de medição, suficientemente amplo, para definir camponês como um processo, um ente histórico inserido num quadro social mais amplo de dominação social. De forma que, para Shanin:

(...) enquanto o impacto de organizações sociais mais amplas (feudalismo, absolutismo, "despotismo oriental" e assim por diante) que "circundam" as plantações da família camponesa foi inconfundível e poderoso, ainda assim não destruiu grandes similaridades "genéricas" da economia camponesa e da sua estrutura social em diferentes partes do mundo. (Shanin, 1974, p. 186)

Portanto, a heterogeneidade camponesa é expressa na sua diversidade regional, que tem suas raízes no contexto natural, no passado histórico e no contexto social mais amplo. Mas, com base nessa diversidade podemos ver emergirem padrões e sequências de mudanças estruturais. A heterogeneidade também é um reflexo da expressão de grandes diferenças qualitativas de formas econômicas sobre o campesinato (Shanin, 1974, p. 187). Haveria, então, como propõe James Scott (1985, p. 302-303) - outro importante autor da "nova tradição" dos peasant studies - uma forma camponesa de produção que convive com modos de produção outros hegemônicos.

Autores como Owen (2005, p. 379-380), a fim de construir uma coerência teórica dessas perspectivas expostas, retoma um conceito central do marxismo, o de formação econômico-social. Para o autor, isso possibilita entender a duradoura presença camponesa atravessando a história humana. Assim, segundo essa perspectiva, dois modos de produção distintos convivem e interagem, ainda que um seja predominante, o que nos possibilita escapar de uma perspectiva idealizada do campesinato, bem como evitar os mitos de que a inserção nos mercados, invariavelmente, levará a sua destruição.

Entretanto, apesar do refinamento teórico que o conceito "camponês" experimentou ao longo da segunda metade do século XX, na virada do século XXI seguia sendo um termo com sua parcela de críticas. Bernstein e Byres (2001), por exemplo, defendem que o termo "camponês" seria um tipo ideal genérico construído sobre uma noção variada de "camponesidade" através de diversos métodos e intenções ou, como dizem os autores, ideologias. Os elementos dessa camponesidade seriam: 1) produção da terra com trabalho familiar visando autorreprodução; 2) solidariedade, reciprocidade e igualitarismo da comunidade; 3) comprometimento com valores e com uma forma comunal de organização da produção; 4) uma inserção tendencialmente local e; 5) harmonia com a natureza, recorrentemente reivindicado pelos discursos "verdes".

Assim, para esses críticos dos peasant studies, a "essência” camponesa poderia estar relacionada com teorias formais do comportamento camponês ou numa concepção sociológica e cultural(ista) que torna os camponeses diferentes e especiais em relação aos proletários ou aos fazendeiros (focados na produção 
voltada para a venda). De forma que: "[essa] construção essencialista reconhece a relação dos camponeses com outros grupos sociais e entidades - proprietários, mercadores, o Estado, o urbano em geral - e tipicamente os vê como relações de subordinação e exploração que define a condição camponesa e gera política da resistência camponesa" (Bernstein e Byres, 2001, p. 6).

Outra crítica importante é aquela avançada por Ciro Cardoso (2002, p. 35), autor que no final dos anos 1970 tinha operado com o conceito de campesinato dentro de uma visão mais estritamente socioeconômica. Cerca de 20 anos depois, em princípios do século XXI, diz que “'campesinato' é noção vaga, ampla demais, carregada de estereótipos e de lugares-comuns culturais e políticos." A despeito disso, não advogava em favor do abandono do termo, vista sua importante difusão no seio das Ciências Sociais. Apenas apontava que se deveria trabalhar com "campesinato" como uma categoria imperfeita em sua heterogeneidade para cada período ou realidade histórica especifica, deixando de lado as pretensões unificadoras que poderia ter como um conceito.

Numa tentativa de escapar a essa perspectiva essencialista, uma possibilidade teórica é aquela defendia por Michael Kearney (1996), apresentada dentro do quadro do pós-modernismo durante os anos 1990. Essa abordagem, diferente de outras dentro do paradigma pós-moderno, não recusa o conceito de "camponês", mas o retira do conjunto de outros aparatos teóricos que o dão sentido, como "exploração" ou "modo de produção". A crítica de Kearney, então, é no sentido de tirar o conceito de "camponês" do "essencialismo binário" - exploradores e explorados - do estruturalismo, vendo-o como um "outro". Para ele, portanto, haveria um "pós-camponês", dividido entre uma série de outras identidades.

A perspectiva de Kearney acaba por reduzir o "camponês" a um conjunto de apropriações de símbolos culturais ou a padrões de consumo. Dessa forma, o referido autor reduz os camponeses sob a globalização a consumidores definidos pelo seu poder de compra. Assim sendo, o termo "pós-camponês" remove desse grupo o empoderamento, uma vez que mina dos movimentos camponeses seus elementos identitários que lhes garantem legitimidade e unidade.

Outro autor recente que reivindica o termo camponês como uma ferramenta de análise é Van der Ploeg (2008). Esse autor também busca esquivar-se das críticas de uma conceituação essencialista, mas faz isso sem reduzir o conceito a uma mera questão identitária; assim como, busca justamente compreender as grandes variações internas do campesinato existente, dando grande importância ao caso europeu.

Esse é um dos elementos que permite ao autor avançar críticas aos peasant studies, mas sem romper com o conceito de campesinato. Ele aponta que nos peasant studies não há espaços para os camponeses no mundo moderno, pois sob o ponto de vista dos estudos empíricos, há uma má representação das formas camponesas de produção (Van der Ploeg, 2008, p. 19). Em outras palavras, quando aparecem em países desenvolvidos são tratados como "anomalia”, e quando vemos sua presença em países em desenvolvimento são vistos como um "entrave" que só pode ser superado pela introdução de técnicas empresariais.

Por sua vez, quando práticas empresariais adotam outras que são caracteristicamente camponesas, isso é abordado como imperfeições temporárias. Além disso, como a maior parte do trabalho agrícola é visto como produto de ações empresariais, a agricultura é posta como mais uma atividade econômica, 
sem qualquer distinção de outros setores econômicos. Assim, desse ponto de vista, a agricultura deve estar alinhada e ser governada pelo mercado (Van der Ploeg, 2008, p. 19-20).

Van der Ploeg ainda faz outras críticas bastante interessantes aos estudos camponeses. Uma delas é o fato de haver uma desatenção quanto à forma da agricultura camponesa, considerando evidente o laço com o ato de cultivar, mas sem refletir sobre o "como" esse processo é realizado. Outra ainda seria a existência de um dualismo - camponês $\mathrm{X}$ fazendeiro capitalista ou camponês $\mathrm{X}$ proletário - que não se verifica na realidade e empobrece a análise enrijecendoa em categorias estanques.

Como forma de contornar esse problema, ele diz que camponês é um conceito que apreende uma realidade que é necessariamente dinâmica, havendo fazendeiros em processo de migração para práticas agroecológicas de caráter campesino e vice-versa. Dessa forma, para Van der Ploeg, o campesinato como uma categoria rígida seria um tipo ideal que existiria apenas na teoria. Ou seja, não sendo, por exemplo, sempre fácil estabelecer um corte claro entre o camponês e a população não agrícola (Van der Ploeg, 2008, p. 36). ${ }^{4}$ Assim, os camponeses seriam grupos atravessados por zonas nebulosas nas quais se expressariam os graus de camponesidade. Para dar conta, então, do campesinato como um fenômeno real e de maneira nuançada, Van der Ploeg define camponês como aquele que experimenta a condição camponesa, a qual é caracterizada através da:

(...)luta pela autonomia que é realizada num contexto caracterizado pelas relações de dependência, marginalização e privação. Visa e se materializa como a criação e desenvolvimento de uma base de recursos autocontrolada e autogerida, a qual por sua vez permite que essas formas de coprodução de homens e natureza que interage com o mercado, permite a sobrevivência para perspectivas futuras e reforça e fortalece a base de recursos, melhora o processo de coprodução, aumenta a autonomia e, portanto, reduz a dependência. Dependendo das particularidades da conjuntura socioeconômica vigente, tanto a sobrevivência e o desenvolvimento da própria base de recursos pode ser reforçada através do envolvimento em outras atividades não agrárias. Finalmente, estão presentes padrões de cooperação que regulam e fortalecem essas inter-relações.(Van der Ploeg, 2008, p. 23)

Nesse sentido, a perspectiva proposta pelo autor parece bastante interessante e parte de maneira bastante direta daquilo que venho chamando de "nova tradição" dospeasant studies, mas utilizando uma ideia de "camponesidades" que possibilita romper com as perspectivas demasiado rígidas. Além disso, desloca um dos eixos centrais do conceito que para Shanin e Wolf estaria na dominação - portanto, uma "característica passiva" - para enfocar na resistência dos camponeses à subjugação. Essa inversão permite valorizar a agência camponesa frente aos poderes constituídos e não apresenta esse grupo como um mero joguete nas mãos da classe dominante.

Segundo tal proposição, camponês é aquele que experimenta a condição camponesa conforme descrita acima. Em que pese a relativa tautologia da proposição, trata-se de uma proposta útil para estabelecer análises comparativas, como entre América Latina e Europa, que guardam relações tão diferentes no campo, e avaliar as distintas dinâmicas diacrônicas experimentadas. Justamente a questão de como esse conceito pode ser operado em diferentes temporalidades é de extrema importância para o trabalho agora realizado, sobretudo no que se refere aos contextos pré-capitalistas. Algo que de maneira nenhuma redunda 
em um essencialismo, pois o que permite observar é a enorme variedade das configurações daqueles que trabalham a terra no tempo e no espaço, mas isso sem perder de vista as nuanças internas nem a transformação diacrônica experimentada.

Além disso, a ideia de que camponês é aquele que experimenta a condição camponesa se mostra de grande valia para o estudo do pré-capitalismo. Isso porque, por exemplo, ainda que não haja "fazendeiros capitalistas" ou "proletários" no período medieval, temos o registro de uma pluralidade enorme de condições jurídicas daqueles que trabalham a terra. Essa enorme quantidade de termos legais para se referir aos que cultivam o solo é um dos argumentos que, como mencionei anteriormente, é levantado para negar o conceito de "camponês" para Idade Média em prol do uso de palavras de época que fragmentam profundamente a realidade social e impedem uma análise totalizante.

\section{Campesinato na historiografia sobre a Alta Idade Média}

Percorrido esse debate teórico, parece necessário contrastar essas leituras com os raros casos em que há alguma tentativa de enquadramento conceitual do termo "camponês" na historiografia sobre a Alta Idade Média. Por exemplo, no importante livro lançado por Chris Wickham temos um dos poucos esforços de definição do que seria o "campesinato" por ele estudado. Seguindo sua proposição, camponês seria: “(...) um cultivador assentado (ou, mais raramente, pastor), cultivando em larga medida para subsistência, que faz pelo menos algum trabalho agrícola pessoalmente, e que controla o seu trabalho na terra" (Wickham, 2005, p. 386). Definição desse agente social que não dista muito daquelas propostas da nova tradição dos peasant studies, o que como vimos pode trazer problemas pelo fato de não dar conta de nuances e do processo dinmico que é a vida camponesa.

Já para João Bernardo (1995, p. 16) no volume I de sua síntese sobre o ocidente medieval, campesinato é a "população da área em que o regime senhorial prevalecia e que era obrigada a aceitá-lo como forma de poder, sem que porém integrasse as suas instituições socioeconômicas”. Àqueles que teriam entrado nos laços de dependência com a aristocracia o autor usa outro termo, o de servo. Opção que toma pelo fato de ter como foco justamente a expansão do sistema senhorial através de um duplo processo, a incorporação dos camponeses livres e o assentamento dos escravizados em lotes de terra.

Outro autor que tentará lidar com essa questão é o arqueólogo Tejerizo García (2017, p. 59-60). Partindo de um debate mais específico ao marxismo, ele enquadra o campesinato como uma classe social. $\mathrm{O}$ que de maneira nenhuma seria uma homogeneização, contendo em seu seio várias facções, grupos e subgrupos.

Assim sendo, para o autor, o campesinato seria uma classe social do ponto de vista da análise, estando na sua diversidade em oposição a uma aristocracia que por sua vez seria também heterogênea. $\mathrm{O}$ próprio autor reconhece que a conceituação do campesinato como classe social assume um forte caráter estruturalista, necessário quando se trata de avançar em definições. Buscando alternativas para superar essa perspectiva, propõe que o conceito "deve ser posto 
em movimento" com a análise concreta da dinâmica histórica, ou seja, a partir da análise da luta de classes.

Apesar da forma como Tejerizo García mobiliza essas referências teóricas ser coerente com o estudo arqueológico que propõe, elas talvez não sejam as mais adequadas para lidar com a diversidade de estatutos sociais que aparecem na documentação textual. Afinal, ele mesmo destaca que há uma distinção ontológica entre as fontes de natureza arqueológica e aquelas escritas (Tejerizo García, 2017, p. 38). Esse é um fator que talvez leve à necessidade de refinar a conceituação que ele avança no caso de estudos que venham a estar informados pelas demandas teóricas impostas por fontes de ontologias distintas.

Nesse sentido, vejo como profícuo uma interlocução dessa perspectiva classista com a apontada por Van Der Ploeg (2008, p. 17-52) que defende ser "camponês" aquele que experimenta a "condição camponesa" historicamente. Condição experimentada de forma que conceitualmente independeria de outras atividades produtivas também realizadas ou do status daquele que a exercer.

\section{Uma proposta de conceituação}

As reflexões feitas até aqui nos remetem ao conceito de experiência de E. P.Th ompson, ${ }^{5}$ e que, se posto nos termos apontados por Van Der Ploeg, nos permitiria uma apreensão mais precisa do campesinato altomedieval sempre que lidarmos de forma conjugada com as fontes escritas e as provenientes da cultura material. Ou seja, entendendo o campesinato como uma classe social. ${ }^{6}$

Evidentemente, não como uma "classe para si" e com consciência de sua ação política (Astarita, 2000; Araujo e Cardoso, 2006, p. 92-93), mas como um agente coletivo que emerge na análise a partir da sua ação nas lutas sociais contra a aristocracia que tem interesses opostos aos dos camponeses. Nesse sentido, me vinculo a uma tradição thompsoniana segundo a qual o conceito de luta de classes é central, visto que permite abordar a classe como um processo conflitivo, sem implicar que houvesse a necessidade de compreensão disso em termos classistas pelos próprios agentes históricos (Mattos, 2012, p. 89).

Assim, a referida "condição camponesa" que menciona Van der Ploeg pode ser lida pela chave de análise que propõe Thompson (1978) através do conceito de experiência. De forma que a experiência camponesa é o que nos permite ver o campesinato dentro de uma concepção classista no curso do processo histórico e manifesta na luta social. Ou seja, o campesinato não existe por si próprio. Podemos apenas identifica-lo como um agente social quando o vemos em oposição com uma classe outra que tenta ampliar os níveis de exploração aos quais aqueles que trabalham o solo estão submetidos.

Portanto, através desse cruzamento proposto entre conceito de camponês e o marxismo, creio que seja possível apreender um sujeito social nas suas especificidades históricas, de maneira que seja capaz de fornecer uma ferramenta teórica que nos permita compreender os que lavram a terra em sua diversidade, normalmente tão fugidia nos documentos. Creio que dentro dos marcos que avancei possa superar as questões ontológicas de fontes de natureza tão diversa e produzir uma análise que integre documentação escrita e arqueológica.

A conceituação proposta me permite abarcar de forma integrada e complexa realidades sociais tão variadas como os jornaleiros - mercenarius - relatados 
na Vida de São Milão (Vazquez de Praga, 1943, p. 26-27) quanto os que aparecem fazendo os pagamentos referidos nas pizarras visigodas. ${ }^{7} \mathrm{Ou}$ ainda compreender como um mecanismo de resistência camponesa as fugas de dependentes tão presentes na documentação altomedieval, em especial na $L e x$ Visigothorum(Bonnassie, 1993). Isso para citar apenas alguns exemplos do caso Ibérico altomedieval.

Com base nesse enquadramento do conceito de camponês talvez sejamos capazes de conjugar de maneira mais plena do que foi possível até agora as fontes textuais e as arqueológicas. Afinal, a imensa diversidade jurídica para caracterizar os que cultivam a terra é quase absolutamente invisível através dos registros materiais por eles deixados.

As aldeias que se proliferam pelo campo europeu ao longo dos primeiros séculos medievais (Vigil-Escalera Guirado, 2007) apresentam tendencialmente poucos indícios arquitetônicos de diferenciação social. Isso não quer dizer que essas diferenças necessariamente não existissem, apenas que sua percepção arqueológica não é facilmente reconhecida. Em várias partes do mundo ibérico da Alta Idade Média a exceção parecer ser o registro funerário que apresenta, em algumas sepulturas, objetos associados aos mortos, os quais foram tradicionalmente interpretados como elementos oriundos dos povos germânicos. Essa tese "germanista" é hoje bastante criticada (Diarte-Blasco, 2018, p. 131-135) com novas interpretações que vinculam esses objetos a estratégias de dominação aristocrática sobre aldeias começando a serem formuladas (Carvajal Castro e Tejerizo García, 2018).

Como o elemento chave no enquadramento que busquei oferecer é a experiência e oposição nas tensões com a aristocracia, podemos articular dentro de uma mesma ferramenta teórica a arqueologia das aldeias e os registros escritos, o que permitirá uma narrativa única acerca do processo de sujeição camponesa ao longo dos primeiros séculos medievais.

Caberia aprofundar melhor reflexões sobre alguns pontos a fim de dar mais substância à proposição aqui realizada. O primeiro deles é estabelecer a dinâmica que relaciona o campesinato com os vários modos de produção, ou se haveria, como propõe Wickham (2005), um modo de produção camponês. Algo que demandaria uma reflexão específica e um espaço maior para desenvolver.

Outro ponto diz respeito à aplicabilidade (ou não) do conceito de campesinato aos escravizados. Não resta dúvida, por exemplo, que um "escravo assentado" (seruus casatus) experiencia a condição camponesa e, portanto, no processo da luta de classes com uma aristocracia que se constitui como antagônica, é, na prática, um camponês. Porém, esse processo é bastante mais nebuloso quando pensamos nos escravos vistos como "instrumentos vocais" frequentemente referido para o período romano ou para o escravista colonial americano.

Menciono apenas um caso do Brasil de fins do século XVIII para ilustrar como esse tema é controverso. Temos o registro de um tratado proposto pelos escravos rebelados a seu senhor, Manuel da Silva Ferreira, em 1789, no Engenho de Santana na Bahia. Nesse documento os escravizados demandam:

(...) queremos paz e não queremos guerra; se meu senhor também quiser nossa paz há de ser nessa conformidade, (...) nos há de dar os dias de sexta-feira e de sábado para trabalharmos para nós não tirando um desses dias por causa de dia santo. (...) 
Poderemos plantar nosso arroz onde quisermos, e em qualquer brejo, sem que para isso peçamos licença, e poderemos cada um tirar jacarandás ou qualquer pau sem darmos parte para isso. (citado em Reis, 1999, p. 123-124)

Referências como essa suscitaram um grande debate, que foi vigoroso algumas décadas atrás, sobre um fenômeno conhecido como "brecha camponesa" na economia escravista colonial e que mobilizou alguns dos maiores nomes da historiografia de então, da brasileira em particular (Reis, 1999, p. 22-31). O já mencionado Ciro Cardoso (1987) foi um que nos anos 1980 chegou a dizer que teria existido um "protocampesinato negro nas Américas." Alguns outros casos são conhecidos para o continente americano e Caribe, mas os dados que temos são esparsos.

Classificar até mesmo a escravidão como uma outra forma de submissão do trabalho camponês parece ser uma possibilidade quando pensamos sobre as sociedades antigas e medievais. Contudo, verificar essa proposição na documentação já é uma tarefa hercúlea no período colonial moderno, que é comparativamente muito melhor iluminado pelas fontes. Comprovar essa perspectiva para os contextos antigo e medieval é algo ainda mais difícil.

Isso sugere que, ao menos como hipótese, é válido propor que mesmo no caso da forma de controle mais vigorosa do trabalho - a escravidão- ainda haveria possibilidade de experimentar a condição camponesa. Possibilidade que não por acaso emerge nas fontes que registram uma revolta escrava lutando por autonomia relativa, com as classes se constituindo na luta pelo acesso à terra e no usufruto dos seus produtos. Ou seja, talvez seja razoável propor que a escravidão é apenas a forma mais submetida possível do trabalho camponês. Entretanto, isso é um tema que para receber o desenvolvimento que merece demandaria um artigo próprio.

Por fim, resta apenas dizer que o estudo do mundo agrário pelos historiadores que se dedicam à (Alta) Idade Média, através do conceito de campesinato neste texto apresentado, permite não apenas uma compreensão integrada da dominação e exploração durante o período, mas ainda o engrandecimento analítico, aprofundando mais uma experiência histórica capaz de ser apreendida por essa referência conceitual. Não como uma realidade isolada, mas como parte de uma longa história camponesa milenarmente negada e apagada.

\section{Referências}

Anderson, P. (1994). Passagens da Antiguidade ao feudalismo. São Paulo: Editora Brasiliense.

Astarita, C. (2000). ¿ Tuvo consciencia de clase el campesinadomedieval?. Edad media (3).

Bakunin, M. (1870). Letters to a Frenchman on the Present Crisis. Recuperado de https://www.marxists.org/reference/archive/bakunin/works/1870/letter-fre nchman.htm

Barbero, A. e Vigil, M. (1978). La formación del feudalismo en la Península Ibérica. Barcelona: Editorial Crítica.

Bastos, M.J. da M.. (2010). Escravo, servo ou camponês? Relações de produção e luta de classes no contexto da transição da antiguidade à idade média (Hispânia - séculos V-VIII). POLITEIA: História e Sociedade, 10 (1). 
Bernardo, J. (1995). Poder e Dinheiro - Do Poder Pessoal ao Estado Impessoal no Regime Senhorial, Séculos $V-X V(V o l .1)$. Porto: Ediçóes Afrontamento.

Bernstein, H. e Byres, T. (2001). From Peasant Studies to Agrarian Change. Journal of Agrarian Change, 1 (1).

Bloch, M. (1998). Cómo y por qué terminó la esclavitud antigua. In A. A. V. V.. La Transicion del esclavismo al feudalismo. Madrid: EdicionesAkal.

Bonnassie, P. (1993). Supervivencia y Extinción del Régimen Esclavista en el Occidente de la Alta Edad Media (Siglos IV-XI). In Bonnassie, P. Del Esclavismo al Feudalismo en Europa Occidental. Barcelona: Crítica.

Cardoso, C. F. (1987). Escravo ou Camponês? - O protocampesinato negro na América. São Paulo: Brasiliense.

Cardoso, C. F. (2002). Camponês, campesinato: questóes acadêmicas, questóes políticas. In A. L. Chevitarese, O Campesinato na História. Rio de Janeiro: Relume.

Cardoso, C. F. e Araujo, S. R. R. de. (2006). A Sociedade Romana do Alto Império. In G. V. da Silva e N. M. Mendes (Ed.), Repensando o Império Romano. Rio de Janeiro, Mauad; Vitória, EDUFES.

Carvajal Castro, Á. e Tejerizo García, C. (2018). Teorizar el estado en las sociedades precapitalistas: uma aproximación desde el marxismo a las sociedades altomedievales. Comunicación presentada al Congreso Internacional en el 200 aniversario del nacimiento de Karl Marx. Bilbao.

Chayanov, A. (1981). Sobre a teoria dos sistemas econômicos não capitalistas. In J. G. da Silva y V. Stolcke (Eds.), A Questão Agrária. São Paulo: Brasiliense.

Diarte-Blasco, P. (2018). Late Antique and Early Medieval Hispania - Lanscapes without Strategy? An archeological Approach. Oxford: Oxbow Books.

Edelman, M. (2013). What is a peasant? What are peasantries? A briefing paper on issues of definition. Invited paper for the First Session of the Open-Ended Intergovernmental Working Group on a United Nations Declaration on the Rights of Peasants and Other People Working in Rural Areas, UN Human Rights Council, Geneva, July 15-19.

Kearney, M. (1996). Reconceptualizing the peasantry: anthropology in global perspective. Boulder: Westview.

Kropotkin, P. (1893). Advice to Those About to Emigrate. Disponível: https://www.ma rxists.org/reference/archive/kropotkin-peter/1893/advice.htm

Lênin, V. (2017). O Estado e a Revolução. São Paulo: Boitempo.

Löwy, M. (2013). Dialética Revolucionária Contra a Ideologia Burguesa do Progresso. In K. Marx e F. Engels, Lutas de classes na Rússia. São Paulo: Boitempo.

Malinowski, B. (1978). Argonautas do Pacifico ocidental: um relato do empreendimento $e$ da aventura dos nativos nos arquipélagos da Nova Guiné melanésia. São Paulo: Abril Cultural.

Martín Viso, I. (2006) Tributación y escenarios locales en el centro de la Península Ibérica: algunas hipótesis a partir del análisis de las pizarras "visigodas". AnTard, 14.

Marx, K. (2011). O 18 de Brumário de Luis Bonaparte. São Paulo: Boitempo.

Marx, K. e Engels, F. (2013). Lutas de classes na Rússia. São Paulo: Boitempo.

Mattos, M. B. (2012). E. P. Thompson e a tradição de critica ativa do materialismo histórico. Rio de Janeiro: EdUFRJ.

Meillassoux, C. (1973). The social organisation of the peasantry: The economic basis of Kinship. The Journal of Peasant Studies, I (1). 
Mintz, S. (1973). A note on the definition of peasantries. The Journal of Peasant Studies, $1(1)$.

Moore Jr., B. (1983). As Origens Sociais da Ditadura e da Democracia. São Paulo: Editora Martins Fontes.

Musto, M. (2018). A controvérsia sobre o desenvolvimento do capitalismo na Rússia. In M. Musto, O Velho Karl Marx - Uma biografia de seus últimos anos. São Paulo: Boitempo.

ONU. (2018). Declaration on the rights of peasants and other people working in rural areas. Recuperado de http://bit.ly/2MZs7P5 (acessado em 06/01/2020).

Owen, J. (2005). In defence of the "peasant". Journal of Contemporary Asia, 35 (3).

Quirós Castillo, J. A. (2009). Early Medieval Villages in Spain in the light of European experience. New approaches in peasant archaeology. In J. A. Quirós Castillo (Org.), The archaeology of early medieval villages in Europe. Lejona: Servicio Editorial de la Universidad del País Vasco.

Reis, J. J. (1999). Negociação e conflito: a resistência negra no Brasil escravista. São Paulo: Cia das Letras.

Scott, J. (1985). Weapons of the Weak: Everyday Forms of Peasant Resistance. New Haven: Yale University Press.

Sevilla Gusmán, E. e González de Molina, M. (2013). Sobre a evolução do conceito de campesinato. São Paulo: Expressão Popular.

Shanin, T. (1974) The nature and logic of the peasant economy - II: Diversity and change; III: Policy and intervention. The Journal of Peasant Studies, I (2).

Tejerizo García, C. (2017). Arqueología de las sociedades campesinas en la cuenca del Duero durante la Primera Alta Edad Media. Bilbao: Servicio Editorial de la Universidad del País Vasco.

Thompson. E. P. (1978). Eighteenth-Century English Society: Class Struggle without Class? Social History, 3 (2).

Van Der Ploeg, J. D. (2008). The New Peasantries - Struggles for Autonomy and Sustainability in an Era of Empire and Globalization. Londres: Earthscan.

Vázquez de Praga, L. (Ed.). (1943). Vita S. Emiliani. Madrid: CSIC

Velázquez Soriano, I. (2004). Las Pizarras Visigodas - Entre el latín y su disgregación. La lengua hablada en Hispania, siglos VI-VIII. Burgos: Fundación Instituto Castellano y Leonés de la Lengua.

Via Campesina. (2009). Declaration of Rights of Peasants - Women and Men. Documento adotado pelo Comitê Coordenador da Via Campesina Internacional em Seul.

Vigil-Escalera Guirado, A. (2007). Granjas y Aldeas Altomedievales al Norte de Toledo (450-800 D.C.). Archivo Español de Arqueología, 80.

Wickham, C. (2005). Framing the Early Middle Ages - Europe and the Mediterranean 400-800. Oxford: Oxford University Press.

Wolf, E. (1976). Sociedades Camponesas. Rio de Janeiro: Zahar.

\section{Notas}

1 Breve Resenha biográfica: Doutorando no PPGH-UFF, bolsista do Conselho Nacional de Desenvolvimento Científico e Tecnológico (CNPq) e membro do Núcleo Interdisciplinar de Estudos e Pesquisas sobre Marx e o Marxismo - Seção de Estudos Pré-Capitalistas (NIEP-Marx-PréK) e do grupo Translatio Studii. 
2 Originalmente publicado em 1922.

3 Para referir ao menos um exemplo, poderíamos citar Barrington Moore Jr. (1983, p. 141) que enxerga o campesinato como um entrave à modernidade.

4 Uma possibilidade, a título de exemplo, seria uma família camponesa em que um dos membros trabalha com outra atividade remunerada, mas que investe os rendimentos do salário em melhorias da terra ou do maquinário.

5 O conceito de experiência aparece primordialmente na obra A Formação da Classe Operária Inglesa. Para uma introdução ao conceito de classe e experiência como proposto por E. P. Thompson vide (Mattos, 2012: 83-97).

6 Aqui não é o momento mais oportuno para uma alongada discussão sobre o conceito de classe que escaparia aos objetivos centrais deste trabalho, assim remeto para a melhor sistematização do conceito em (Mattos, 2012: 57-116).

7 Existe um debate sobre a natureza desses pagamentos. Enquanto Velázquez Soriano (2004) defende que seriam rendas, Martín Viso (2006) propóe que fossem impostos. De todo modo, essa discussão não altera o argumento aqui colocado. 